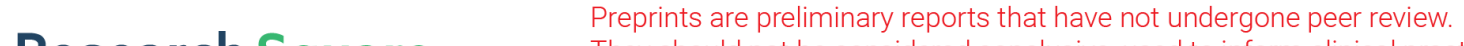 They should not be considered conclusive, used to inform clinical practice, or referenced by the media as validated information. \\ Research and Development of Parametric Design Platform for Series Complex Cutting Tools
}

\section{Zhi Lin}

Harbin University of Science and Technology

Caixu Yue ( $\sim$ yuecaixu@hrbust.edu.cn )

Harbin University of Science and Technology

\section{Desheng Hu}

Harbin University of Science and Technology

Xianli Liu

Harbin University of Science and Technology

Steven Y. Liang

Georgia Institute of Technology

Zhipeng Jiang

Harbin University of Science and Technology

Anshan Zhang

Harbin University of Science and Technology

Daxun Yue

Harbin University of Science and Technology

\section{Research Article}

Keywords: Parametric design, Customized tools, Secondary development, ISO 13399, Platform development

Posted Date: December 10th, 2021

DOI: https://doi.org/10.21203/rs.3.rs-1129793/v1

License: (c) (i) This work is licensed under a Creative Commons Attribution 4.0 International License.

Read Full License 


\title{
Research and Development of Parametric Design Platform for Series
}

\section{Complex Cutting Tools}

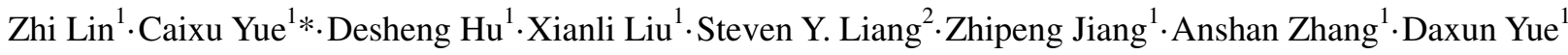

(1. Key Laboratory of Advanced Manufacturing and Intelligent Technology, Ministry of Education, Harbin

University of Science and Technology, Harbin 150080, People's Republic of China

2. George W. Woodruff School of Mechanical Engineering, Georgia Institute of Technology, Atlanta 30332, USA)

Abstract: Metal cutting tool is an important part of machining, and its performance directly affects the manufacturing efficiency and machining quality of products. With the increasing demands in manufacturing industry of cutting performance, machining efficiency, customization and quick response, traditional tool design methods can no longer meet the above requirements due to many repetitive work, large amount of calculation, complex process and low efficiency. Parametric design has become a new development direction of customized tool design because of its fast, stable and accurate characteristics. In this paper, the parametric design of cutting tools is realized based on the process construction method of model generating history. The tool parametric design platform is developed by the method of secondary development of commercial CAD software. The platform realizes automatic operation in the background without the main interface of CAD software, completes the parametric modeling process of tools, generates 2D drawings and 3D models conforming to ISO 13399 standard, and realizes the cloud storage function of model data. The platform has simple operation and good man-machine interaction, and realizes the parametric design of many kinds of tools. Compare with that traditional modeling method, using this parametric modeling platform, the modeling efficiency is increased by $90 \%$ on average. This platform is of great significance to improve the design efficiency of complex customized tools and shorten the original design cycle by $30 \%$.

Keywords: Parametric design, Customized tools, Secondary development, ISO 13399, Platform development

\section{Declarations}

\section{Funding}

This work was supported by The National Key Research and Development Program of China (2019YFB1704800).

\section{Conflicts of interest/Competing interests}

The authors declare that there is no conflict of interests regarding the publication of this article.

\section{Availability of data and material}

The datasets used or analyzed during the current study are available from the corresponding author on reasonable request.

Code availability (Not applicable)

\section{Authors' contributions}

Caixu Yue and Zhi Lin contributed to the concept and background of the study. Zhi Lin has carried on the establishment of the parametric equation of the milling cutter edge, the establishment of the parametric model of cutters and the design and development of the parametric design platform. Daxun Yue contributed to the milling cutter parameter measurement experiment. Xianli Liu, Steven Y. Liang, Zhipeng Jiang, Anshan Zhang, Desheng $\mathrm{Hu}$ and Daxun Yue helped perform the analysis with constructive discussions.

\section{Ethics approval}

The content studied in this article belongs to the field of metal processing, does not involve humans and animals. This article strictly follows the accepted principles of ethical and professional conduct.

* Corresponding author: Caixu Yue

E-mail: yuecaixu@ hrbust.edu.cn 


\section{Consent to participate}

My co-authors and I would like to opt in to In Review.

\section{Consent for publication}

I agree with the Copyright Transfer Statement.

\section{Introduction}

With the development of modern material technology, more and more high-performance and difficult-to-machine materials are applied to aviation, automobile, energy and other mechanical manufacturing fields, such as titanium alloy, wear-resistant cast iron and high-strength structural steel [1]. Traditional tools can't meet the requirements of surface quality, dimensional accuracy, machining efficiency and tool life in new material processing. Therefore, it is necessary to develop complex cutting tools with highly customized requirements. In the process of designing customized tools, designers need to fully consider the characteristics of the machined parts, so that the tools can achieve cutting performance such as vibration suppression, high precision and high efficiency, which cannot be achieved by standardized tools. Therefore, the structure of the tools has undergone tremendous changes. Although the traditional tool design method is mature, it still has many shortcomings, such as repetitive work, large amount of calculation, complicated process and low efficiency, which has been unable to meet the research and development needs of customized tools. Parametric design has become an effective method for custom tool design because of its high efficiency, simplicity and ease of use. In the process of designing customized tools,3D CAD software has been widely used for parametric design of tools. However, developing an independent parametric design platform for cutting tools is long in cycle, high in cost and difficult. Therefore, secondary development based on CAD software has become a new research direction [2].

At present, many scholars have studied the parametric design of cutting tools. Tzotzis et al. $[3,4]$ established a tool design platform which can be used to generate a standardized CAD model of turning inserts by using SolidWorks API and Visual Basic for Applications (VBA) programming language, and imported it into DEFORM-3D. The accuracy of the model was verified by simulation and experimental results, and the influence of nose radius on the cutting force was studied. Krol et al. [5] established a three-dimensional parametric model of gear hob with APM WinMachine parametric toolbox in APM Studio module environment, and analyzed the stress and strain state of the working surface of hob. Nasri et al. [6] established three-dimensional parametric models of face milling cutter and ball-end milling cutter by CATIA software, which were used for finite element simulation of milling process. Chang [7] uses CATIA 3D modeling software and Visual Basic (VB) development technology. The parametric design system of ball-end milling cutter is established. Zhu [8] and Chen [9] combined VB user interface and CATIA macro programming technology, developed a parametric design system for fillet end mills. The end milling cutter model is imported into Third Wave AdvantEdge software for finite element simulation, and the simulation results are used to guide the optimal design of the cutter. Li et al. [2] made use of UG/open API, MenuScript, UIstyler and C/C++ and other modules to carry out the secondary development of UG NX platform, which combined parametric design with the development of two-dimensional drawing of integral cemented carbide end milling cutter, and realized the computer-aided rapid design of end milling cutter. Ding et al. [10] developed a ball-end milling cutter design system integrated with SIEMENS NX and ANSYS on the platform of Visual Studio 2008, which can generate a three-dimensional model of the cutter on SIEMENS NX. And according to the information provided by the user, continue the simulation on ANSYS. Ding et al. [11] established a milling force simulation system on UG platform based on the existing milling force model of ball-end milling cutter, and realized the integration of geometric simulation and physical simulation. Ji et al. [12,13] completed the parametric design of face milling cutter series by using UG/open API secondary development technology. The finite element modal analysis is carried out by Abaqus software. Ding et al. [14] realized parametric modeling and parametric finite element analysis by using UG/OPEN secondary development tool and APDL module of ANSYS software respectively. By compiling the interface program between UG6.0 and ANSYS10.0, the data sharing of CAD/CAE is realized. The remote design and analysis platform is constructed by using ASP.NET technology, component 
technology and database technology. Many scholars have studied parametric design of tools based on UG/Open technology [15-19].

From the above documents, it can be seen that the parametric design system of cutting tools based on secondary development of commercial CAD software at present is almost only aimed at one kind of cutting tools and did not comprehensive. The operation of these systems mostly depends on CAD software windows, and the development process and operation are complicated and the hardware requirements are high. None of the above researches have applied modeling standards in tool modeling, The interaction of tool data is poor. In the world, more and more researches have used ISO 13399 "Representation and Exchange of Cutting Tool Data" (hereinafter referred to as ISO 13399 standard) as the standard for tool modeling [20-24]. The application of tool modeling standard is beneficial to the transmission and interaction of tool data. Therefore, the research and development of parametric design platform for various kinds of tools based on tool modeling standards is of great significance to improve the design efficiency of customized tools.

On the basis of ISO 13399 standard, this paper realized the parametric modeling of customized tools based on the process construction method of generating history, and designed a set of parametric design platform for various customized tools. The advantage of this platform is that it is separated from the main window of NX software, and the parametric design of tools can be realized through the user interface made by Python. The platform can provide simulation models, 3D tool model and 2D drawing conforming to ISO 13399 standard for the research of tool cutting simulation, the construction of digital twin system of tool manufacturing [25] and the tool manufacturing site. Based on the developed platform, the efficiency and accuracy of tool modeling in cutting simulation can be improved and a lot of modeling and drawing time can be saved. Finally, it can improve the efficiency of tool design, shorten the design cycle and reduce the design cost.

\section{Research background}

It is helpful to realize the parameterization, integration and standardization of customized tool design. Designers can reduce a lot of repetitive work by using parametric design technology. Making full use of modern CAD/CAM software to design customized tools can avoid the disadvantages of traditional tool design methods such as large amount of calculation and many decisions. Applying modeling standards in the process of tool design is beneficial to the interaction and transmission of tool model data.

\subsection{Parameterization}

Aviation, automobile and energy are representative industrial fields in machining manufacturing, which have developed rapidly in recent years. The titanium alloy aircraft frame parts shown in Fig. 1 are thin-walled parts with small processing batch and large size. Machining this part requires that the cutting tool has shock absorption function, specialized cutting tool function and high-efficiency and high-precision machining performance. The cast iron automobile engine block part shown in Fig. 2 has complex structure and small processing batch. Machining this part requires the tool to have high structural complexity, customized composite structure and high machining accuracy. The steel nuclear reactor pressure vessel water chamber head shown in Fig. 3 is large in size and processed by heavy cutting. Machining this part requires the tool to have stable performance, high machining efficiency and high precision. Most of the above parts are processed by milling, and the tools shown in Fig. 1 to 3 are frequently used in milling. In this paper, typical complex spiral curved surface cutters, customized reamers and indexable insert milling cutters are selected as research objects. By introducing the structural characteristics of these three types of tools and analyzing the difficulties in tool model design, the necessity of parametric design of tools is illustrated.

Cutting tools with complex spiral surfaces are one of the most widely used milling cutters, including integral end mills and drill bits. In this paper, the integral end mill in Fig. 1 is selected as the main research object. The cutting tool has complex blade shape, adopts unequal pitch and unequal lead design, and has high manufacturing precision. The cutter can effectively inhibit the generation of vibration, Excellent machined surface quality is obtained. The cutter is a five-edge, rounded end mill, and the five circumferential edges are designed in three 
groups. The spiral angles of two adjacent circumferential edges are different and the difference is not more than 2 degrees. Because the tool pitch is different from standard tool and the tip is rounded, it is difficult to model the cutting edge. In order to obtain the optimal design parameters of spiral angle combination, circumferential edge and end edge, Tool models with different design parameters need to be used for simulation, and the modeling workload is heavy. Parametric tool design technology can speed up modeling and improve modeling accuracy.

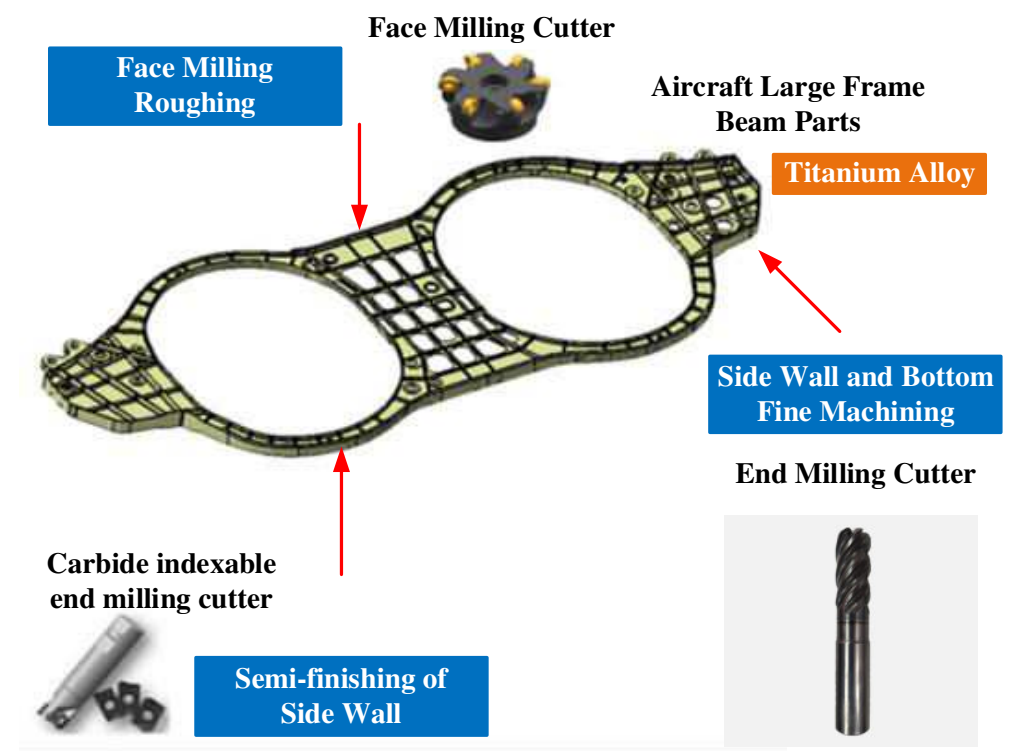

Fig. 1 Titanium alloy frame of aircraft and typical complex tools for machining

Using customized tools in mass production lines can improve production efficiency and machining accuracy. PCD high-precision non-standard customized tools are used in machining hole features such as valve seat guide pipe, spark plug hole and double camshaft hole of engine block. Most of these tools are reamed. In this paper, the special tool for valve seat ring in Fig. 2 is selected as the main research object. This tool is a specialized non-standard tool, and the blades are combined. First, perform rough finishing on the bottom hole of the seat ring catheter, and then perform rough finishing after inserting the upper seat ring and catheter. Because the sizes of inlet and exhaust valves are inconsistent, the required tool structures are quite different. Using the tool parametric design technology can quickly modify the tool structure, generate a new tool model, and save the time wasted by re-modeling. 


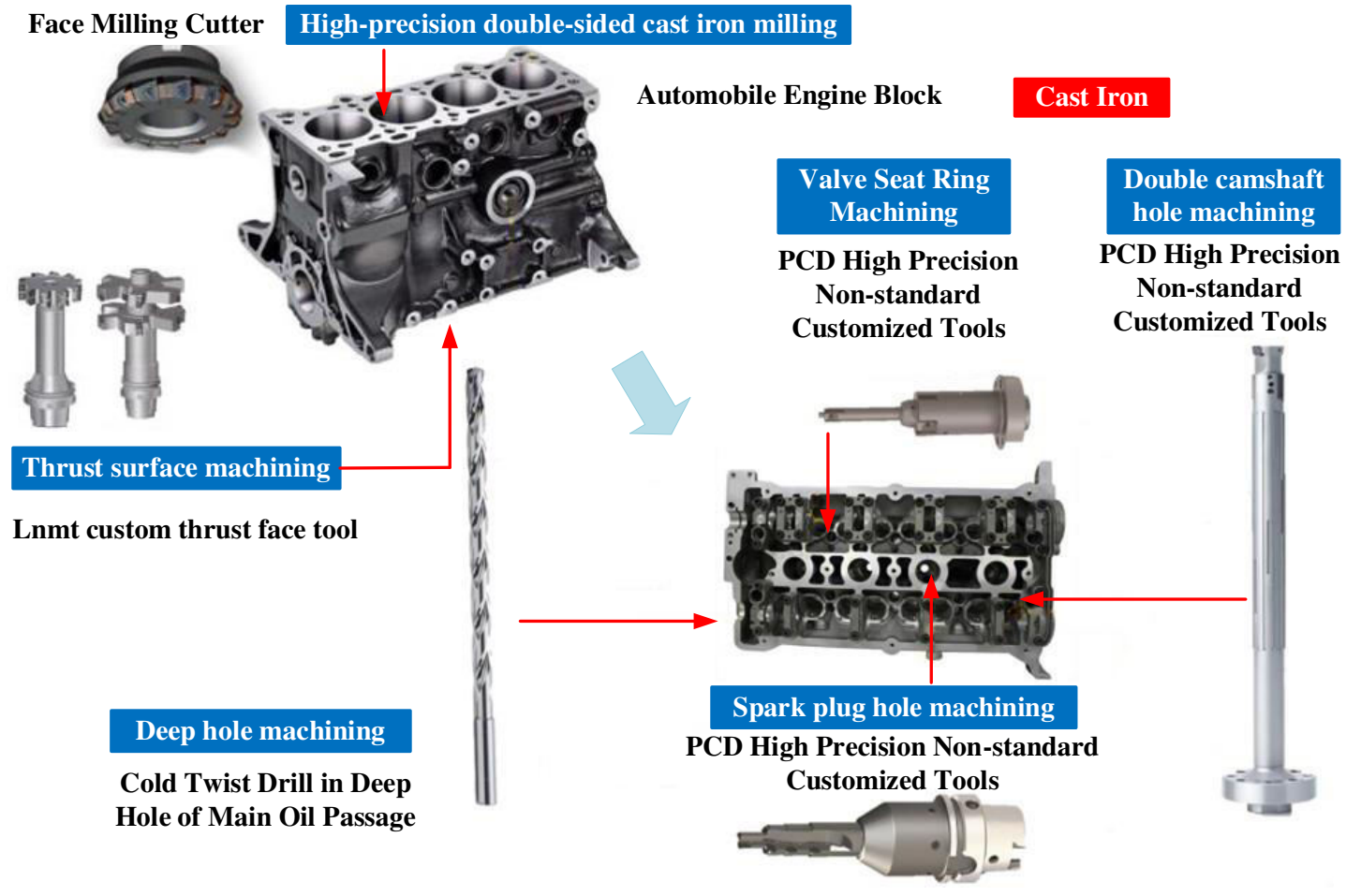

Fig. 2 Automobile engine block and typical complex tools for machining

The indexable insert milling cutter can realize face milling, side milling, square shoulder milling and complex curved surface milling. Face milling cutter is widely used in metal cutting as the main tool of plane machining. In this paper, the face milling cutter in Fig. 3 is selected as the main research object. The face milling cutter blade has a complex blade shape, small main deflection angle and multiple circular arc edges. The design of small main deflection angle can improve the feeding speed of machining and then greatly improve the machining efficiency. When designing this kind of tool, the shape of the tool body will change with the change of the design parameters of the blade. The parametric design technology of the tool can make the blade and the tool body model change synchronously, thus reducing the workload of designers.

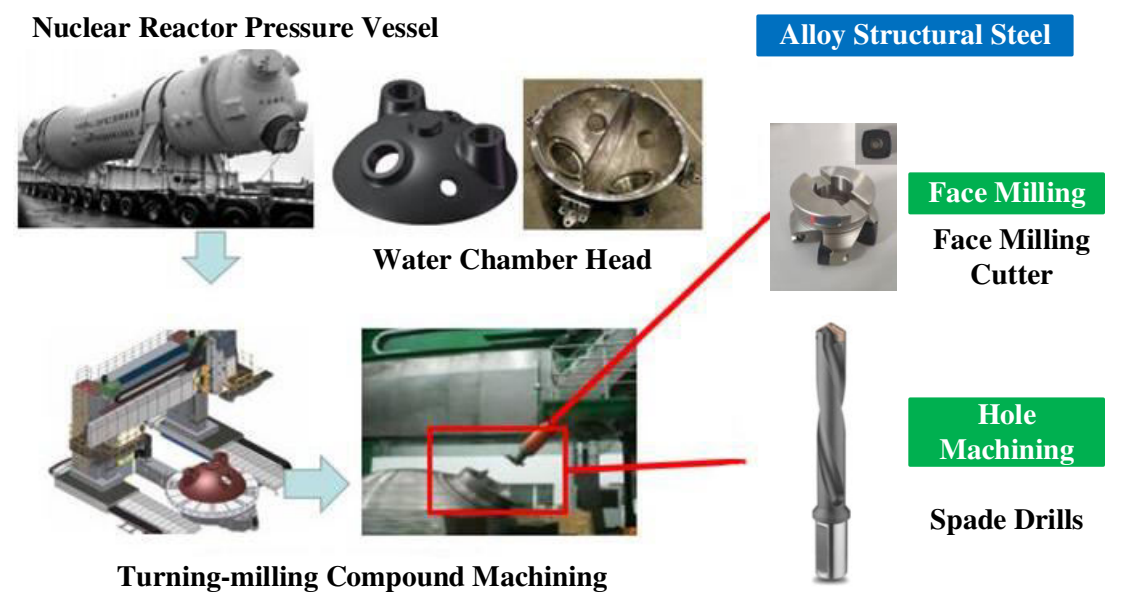

Fig. 3 water chamber head of nuclear reactor pressure vessel and typical complex cutting tools for processing

All the tools described above are customized tools based on specific machining scenes. Although they are similar in appearance to traditional standard tools, their structures have changed greatly in order to meet specific processing requirements. In order to make the cutting tool have the best cutting performance, the designer needs to divide the constant and variable parameters of the tool. Experiment and simulation are carried out for variable parameters, and the best geometric and technological parameters are obtained. Although the technological parameters of the tool can be set by simulation software, the change of the geometric parameters of the tool must be realized by replacing the tool model, so designers need to build a large number of tool models. However, due to 
the complex structure of the customized cutter, the change of one design parameter may make the whole model invalid. And with the change of tool design parameters, the two-dimensional drawings used in tool production also change, so designers need a lot of time to redraw the drawings. Therefore, in order to improve the efficiency of tool design and reduce the workload of designers, it is necessary to develop a tool parametric design platform.

\subsection{Integration}

The traditional tool development process often adopts the traditional mode of "design-trial cutting-improvement", which has the advantages of long development cycle, high cost and low efficiency. The mode of "parametric design-cutting simulation-optimization evaluation" is adopted. After the designers input the design parameters directly through the user interface, the system automatically generates the corresponding 3D model of milling cutter, which greatly reduces the modeling time, it improves the design efficiency and shortens the design cycle. When the performance of the tool is optimized, the designer adjusts the original design parameters and automatically updates the 3D model and 2D drawing of the tool.

Tool design integration is to use programming language and secondary development technology to combine design software, simulation software, analysis software and database to realize the integration of tool design. The principle of tool integrated design platform is shown in Fig. 4. Through the secondary development of CAD and CAE software, the tool model can be quickly designed and directly imported into the simulation model. The tool design and simulation can be connected quickly, and the tool model parametric design and simulation can be combined closely. Using the optimization algorithm, through the analysis of simulation data and the optimization of tool design parameters and cutting process parameters, the optimal design results are found, and the complex tool design process is finally completed. The tool parametric design platform developed in this paper is the source of the standard tool model in the simulation module and the tool manufacturing digital twin module, which plays an indispensable role.

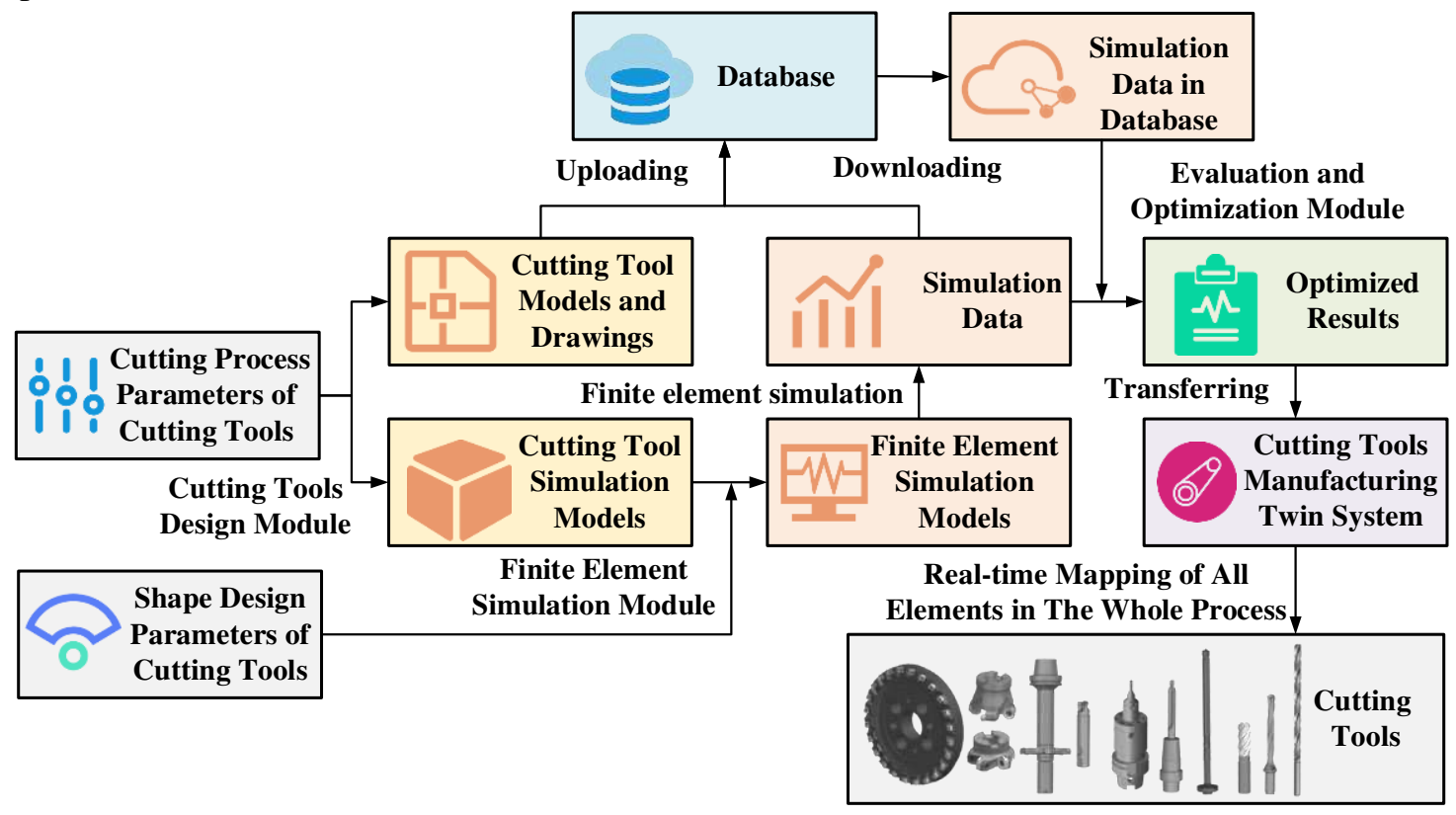

Fig. 4 integrated design principle of cutting tool

\subsection{Standardization}

In order to promote the efficient exchange of information between different environments, systems and applications in the process of tool design and manufacturing, the use of standards will play an important role. The ISO 13399 standard was developed by Sandvik Coromant, Kennametal, Stockholm Royal Institute of technology, CETIM and other stakeholders in the field of metal cutting. The ISO 13399 standard provides the information structure needed to describe the various data of cutting tools and cutting tool components, A method for realizing the electronic representation of cutting tool data is provided [26]. It aims to facilitate the exchange of data in the design, manufacture, distribution and use of cutting tools [27]. ISO 13399 is not a standard to guide the design of 
cutting tools, but a standard for information expression of cutting tools. The structure of the standard is shown in Fig. 5, and a total of 36 sub series standards have been published. In order to facilitate the interaction and transmission of tool model data, the platform developed in this paper uses ISO 13399 as the standard of parametric model establishment.

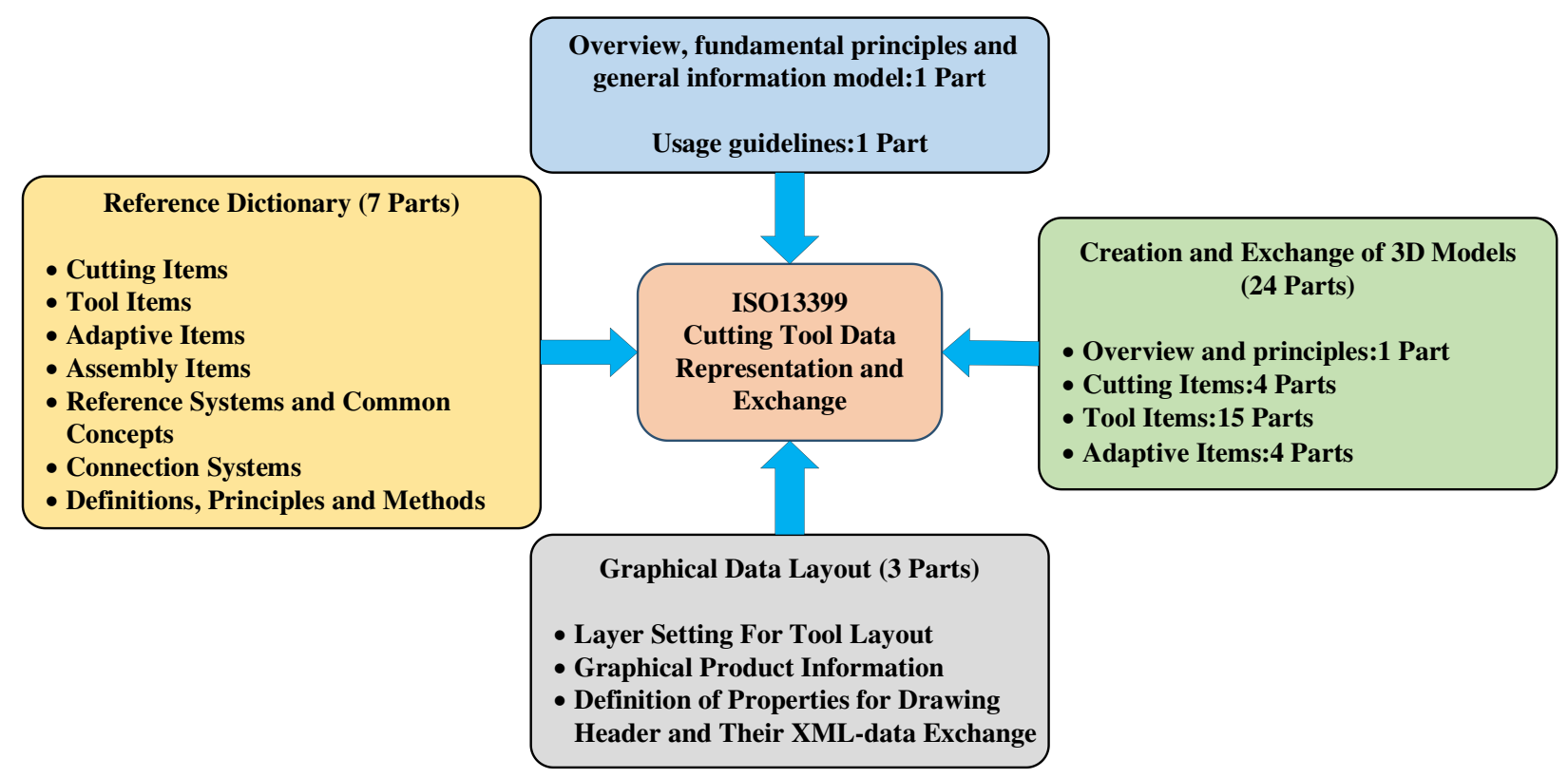

Fig 5 standard structure of ISO 13399

\section{Parametric design technology}

This section introduces the selection of secondary development software and the method of tool parametric design. In order to solve the problem of modeling accuracy of complex spiral surface cutter, the parametric equation of tool edge line of fillet end mill is analyzed and given. In order to improve the accuracy of tool model establishment, tool measurement experiments are carried out according to the existing tools.

\subsection{Selection of development software}

The commonly used commercial CAD software for tool design includes NX, Pro/E, CATIA, SolidWorks, etc. NX is a product engineering solution produced by Siemens PLM Software Company, which has strong secondary development interface and surface modeling advantages.UG/open, the traditional secondary development technology of NX software, provides rich functions and various development modules, which can meet the user-defined requirements of the staff, Developers can use this function to customize the UG system and create functions to meet specific requirements. Therefore, it is an efficient tool design method to realize the parametric modeling of NX.

Although the traditional secondary development function of NX software UG/open is mature, it still needs to rely on NX software main interface to run. Moreover, the programming is more complex, which requires high hardware development, and is not conducive to integration with other cam software. Python is an interpretative, interactive, cross platform and object-oriented language, it has the advantages of easy to read and maintain, perfect basic code base and support mainstream database interaction. The NX software is redeveloped by python, which is separated from the main window of the software. The parametric modeling of the tool model can be realized through the user interface made by python. In addition, python language has been widely used in CAE software such as ABAQUS. Using Python language for secondary development is conducive to the integration and integration of CAD and CAM software. Therefore, this paper chooses the method of secondary development of NX software based on Python language to realize the parametric modeling of tool model.

\subsection{Parametric design method}

In recent years, great progress has been made in the research of parametric design methods, such as variable geometry method based on geometric constraints, artificial intelligence method based on geometric reasoning and 
process construction method based on generation process. The variable geometry method based on geometric constraints needs to use iterative method to solve nonlinear equations, The more complex the model is, the more difficult it is to solve. The artificial intelligence method based on geometric reasoning is built on the basis of complex expert system, and its modeling speed is slow. The process construction method based on generation process is the most mature method, which is widely used in the process of 3D model building of commercial CAD software. When modeling with this method, the model entity is obtained by geometric constraints and Boolean operations, and the model feature information is taken as variable parameters. The new 3D model can be obtained by changing the parameters in a reasonable range and updating the generation history of the model. The modeling is accurate and fast. Therefore, in this paper, the process construction method based on generation history is chosen to design customized tools parametrically.

Expression is an important part of tool parametric design by NX software, and it is the carrier of model variable parameters in process construction method. The expression is characterized by expressing the relationship among various parameters through functional relations, and the parameters can be defined as numbers and formulas. The tool can be modified by modifying one or several parameters in that expression, The realization principle of parametric design is shown in Fig. 6. Expressions can also store title bar information of 2D drawings. According to the main design parameters of cutting tools in the cutting process, this design method can quickly generate different size models from tool models with the same design features and simultaneously generate new 2D drawings, 3D models and 3D simulation models. The modeling efficiency and modeling accuracy are greatly improved.

In order to solve the problem that the user's hardware can't use NX software smoothly because of its low performance, it is necessary to realize the function of fast parametric design without running the main interface of NX software. In this paper, the "run_journal.exe" program in NX software directory "ISiemenslNX18994NXBIN" is selected for secondary development. Firstly, Python language is used to record the generation history file of parametric tool model. Secondly, compile a batch file in bat format, and the driver in this file can run the "run_journal.exe" program in the background and read the generated history file. Finally, the batch file can be called by Python logic program to realize the function of modeling away from the main interface of NX software.

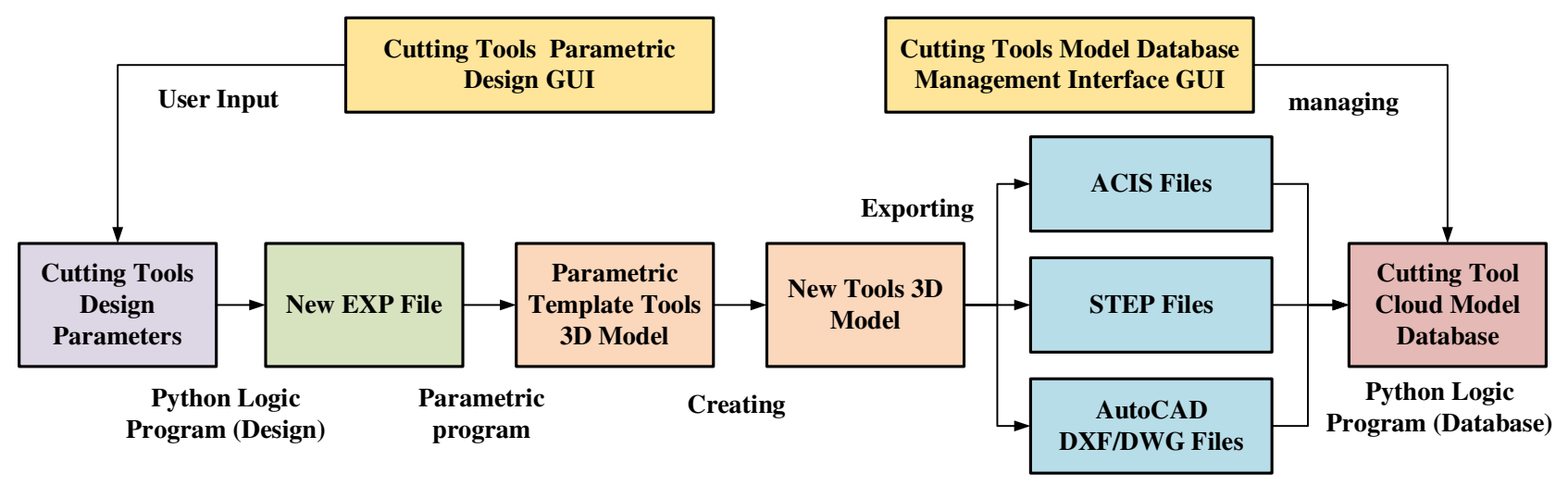

Fig. 6 Implementation principle of parametric design of cutting tools

\subsection{Parameter equation of milling cutter edge line}

The accuracy of tool modeling is one of the important factors for the accuracy of simulation results, and this influence is particularly significant in the edge modeling of integral end mills. In this section, the integral fillet end milling cutter in Fig. 1 is taken as an example, and a continuous cutting edge curve model is established by using the equal lead helix of rotary cutter. In Fig. 7, in the coordinate system of the end mill with rounded corners, the equation of the blade line is expressed by rotating $\varphi$ angle at any point $P$ on the blade line. In the following, the edge line type of the fillet end milling cutter is analyzed and the parameter equation about the parameter $t$ is given. 


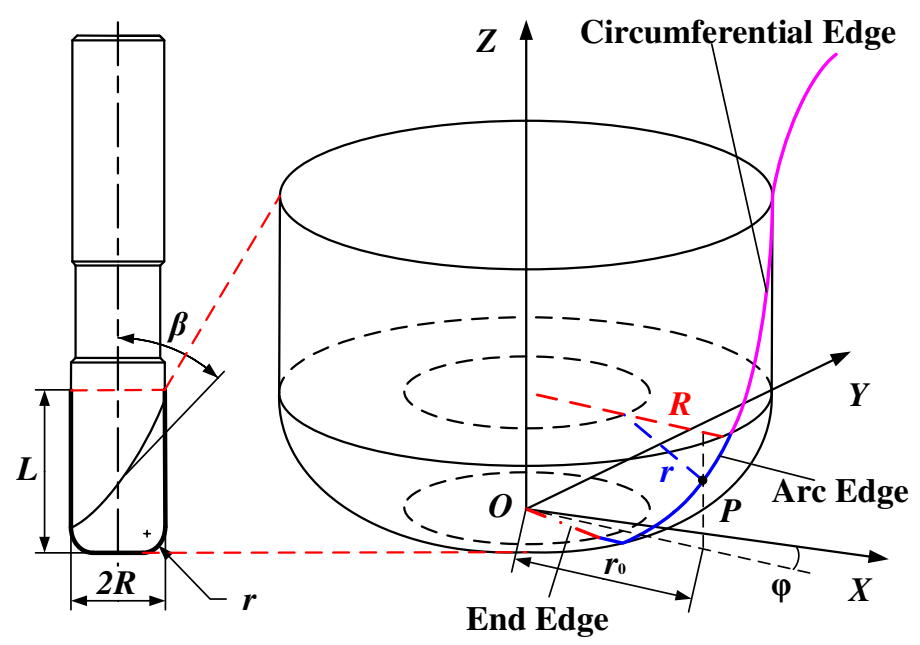

Fig. 7 Coordinate system of integral fillet end milling cutter

(1) The line of circumferential edge

When the curve of the circumferential edge rotates around the $\mathrm{Z}$ axis, the equation $r_{1}$ of the surface of revolution is shown in Eq. 1.

$$
r_{1}=\left\{\begin{array}{c}
R \cos \varphi_{1} \\
R \sin \varphi_{1} \\
r+(L-r) t
\end{array}\right\} \varphi_{1} \in[0,2 \pi], t \in[0,1]
$$

where $R$ is the radius of the cutter body, $r$ is the rounded corners of the cutter, and $L$ is the length of edge line. The tangential vector and meridian vector of the cutting-edge curve of point $P$ in Eq. 2 are respectively $d_{r_{1}}$ and $\delta_{r_{1}}$.

$$
\left\{\begin{array}{l}
\mathrm{d}_{r_{1}}=r_{1 \mathrm{t}} \mathrm{d} t+r_{1 \varphi} \mathrm{d} \varphi_{1} \\
\delta_{r_{1}}=r_{1 \mathrm{t}} \delta t \\
\mathrm{r}_{1 \mathrm{t}}=\{0,0, L-r\} \\
r_{1 \varphi}=\left\{-R \sin \varphi_{1}, R \cos \varphi_{1}, 0\right\}
\end{array}\right.
$$

where $r_{1 \mathrm{t}}$ is the first partial derivative of $r_{1}$ with respect to $t$ and $r_{1 \varphi}$ is the first partial derivative of $r_{1}$ with respect to $\varphi$. Using the first basic form of curved surface as Eq.3 and 4, we can find the angle between $d_{r_{1}}$ and $\delta_{r_{1}}$ on the surface, the helix angle $\beta$.

$$
\begin{aligned}
\cos ^{2} \beta & =\frac{(L-r)^{2} d t^{2}}{(L-r)^{2} d t^{2}+R^{2} d \varphi_{1}^{2}} \\
\mathrm{~d} \varphi_{1} & =\frac{(L-r) \tan \beta}{R} \mathrm{~d} t
\end{aligned}
$$

When $t=0$ and $\varphi=0$, the integration of Eq.4 yields Eq.5.

$$
\varphi_{1}=\frac{(L-r) \tan \beta}{R} t
$$

Substituting Eq.5 into Eq.1, the parameter equation of the circumferential edge helix $f\left(x_{\mathrm{t} 1}, y_{\mathrm{t} 1}, z_{\mathrm{t} 1}\right)$ of the round 
end milling cutter with respect to $t \in[0,1]$ is Eq.6.

$$
\left\{\begin{array}{l}
x_{\mathrm{t} 1}=R \cos [180 t(L-r) \tan \beta /(\pi R)] \\
y_{\mathrm{t} 1}=R \sin [180 t(L-r) \tan \beta /(\pi R)] \\
z_{\mathrm{t} 1}=r+(L-r) t
\end{array}\right.
$$

(2) The line of arc edge

The curve of circular arc and the curve of circumferential edge belong to equal lead helix, and the equation of circular arc edge line is calculated according to the existing equation of circumferential edge line. Eq.7 can be seen from Fig. 5.

$$
r_{0}=R-r+r \sqrt{1-t^{2}}
$$

where $r_{0}$ is the radius of rotation of point $P$ in the XOY plane.Eq. 8 can be obtained in the same way by Eq.5.

$$
\varphi_{2}=\frac{r \tan \beta}{R} t
$$

The parameter equation of the arc edge curve $f\left(x_{\mathrm{t} 2}, y_{\mathrm{t} 2}, z_{\mathrm{t} 2}\right)$ of the fillet end mill with respect to $\mathrm{t} \in[0,1]$ is Eq.9.

$$
\left\{\begin{array}{l}
x_{\mathrm{t} 2}=\left(R-r+r \sqrt{1-t^{2}}\right) \cos [180 t r \tan \beta /(\pi R)] \\
y_{\mathrm{t} 2}=-\left(R-r+r \sqrt{1-t^{2}}\right) \sin [180 t r \tan \beta /(\pi R)] \\
z \mathrm{t} 2=r(1-t)
\end{array}\right.
$$

(3) The line of the end edge

The line of the end edge is a straight line passing through the center o on the XOY plane and tangent to the curve of the circular arc edge. The parameter equation of the edge line $f\left(x_{\mathrm{t} 3}, y_{\mathrm{t} 3}, z_{\mathrm{t} 3}\right)$ of the end edge of the fillet milling cutter with respect to $t \in[0,1]$ is Eq.10.

$$
\left\{\begin{array}{l}
x_{\mathrm{t} 3}=(R-r) \cos [180 r \tan \beta /(\pi R)] t \\
y_{\mathrm{t} 3}=-(R-r) \sin [180 r \tan \beta /(\pi R)] t \\
z_{\mathrm{t} 3}=0 * t
\end{array}\right.
$$

The expressions of cutting-edge curves edited according to Eq.6,9 and 10 are imported into NX software, and the cutting-edge curves shown in Fig. 8 are obtained.

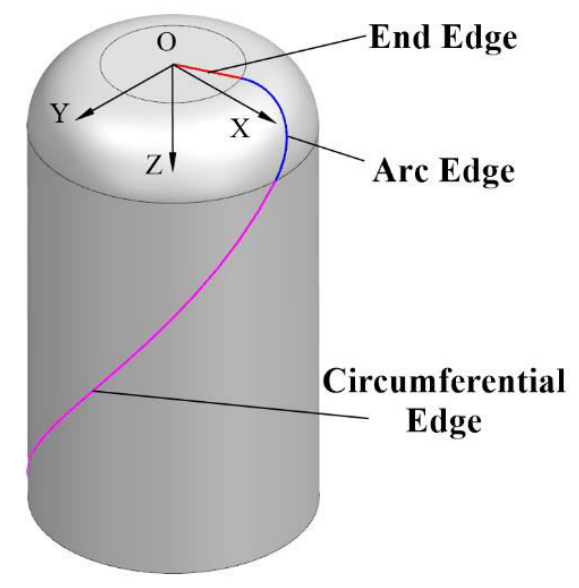

Fig. 8 Cutter edge curve 


\subsection{Milling cutter parameter measurement experiment}

In order to establish the tool model more accurately, the full-scale measurement experiment of the tool shown in Fig. 10 was carried out by using the ultra-depth-of-field microscope shown in Fig. 9. During the experiment shown in Fig. 10, the overall structure, spiral angle, circumferential edge size and end edge size of the tool were measured in turn. Tab. 1 lists the measurement results of the main parameters of the tool. The data in Tab. 1 will be used in the subsequent research of tool model establishment.

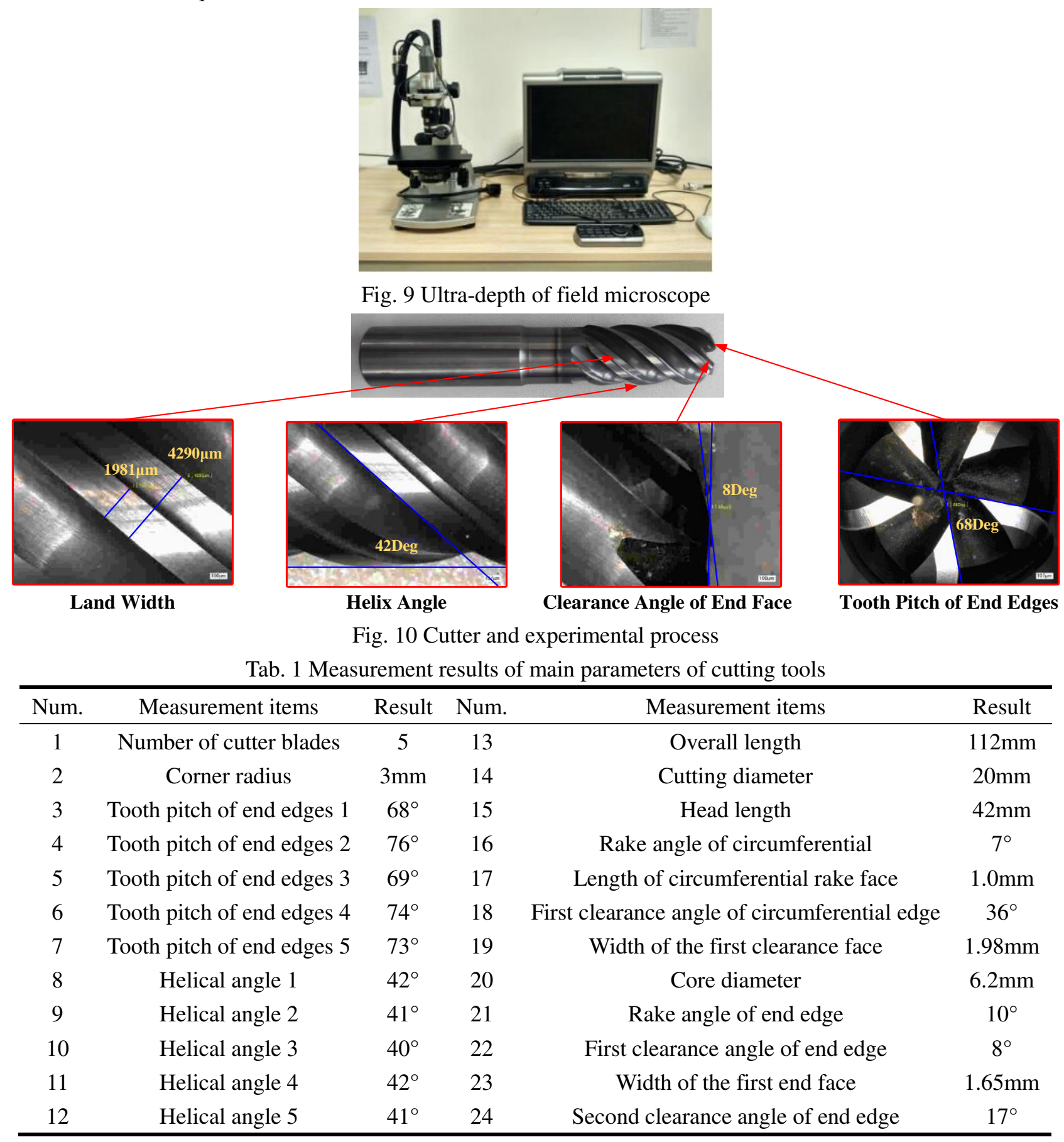

\section{Development of parametric design platform}

The necessity of realizing parametric design and the technology of tool parametric design were introduced. In this section, a parametric design platform for various customized tools is developed based on Python language from the perspective of user application examples.

\subsection{Design scheme}

Parametric design platform adopts modular design structure, and the platform structure is shown in Fig. 11. The user can input design parameters through the parametric design interface to generate new tool model data, and 
view the model data generated by the above design through the model browser in the model browsing module. You can also manage the tool model database through the database management interface.

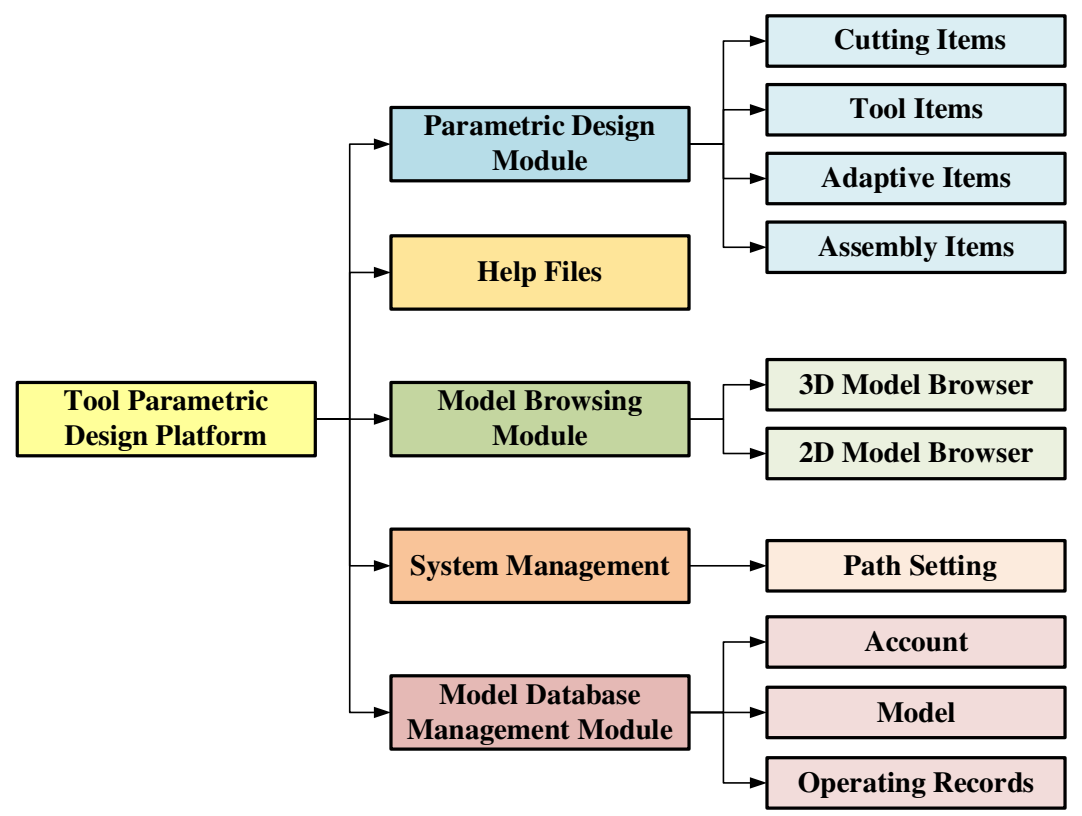

\subsection{Interface design}

Fig. 11 Structure of parametric design platform for cutting tools

(1) User interaction module

In order to facilitate users to complete the parametric design process without complete professional knowledge, the platform designed a series of user interaction functions. In this paper, PyQt5 plug-in made by Python GUI is used as the development tool of platform interface. The main interface of tool parametric design platform as shown in Fig. 10 is established with PythonOCC as the core. The main function of the main interface is to integrate all the contents of parametric design module and database module, and has the function of browsing 3D model. For the convenience of users, the platform built a two-dimensional graphic browser as shown in Fig. 12 with Python's two-dimensional drawing display plug-in ezdxf as the core. In addition, the main interface is also provided with a help function. Used to guide users to complete parametric design operations.

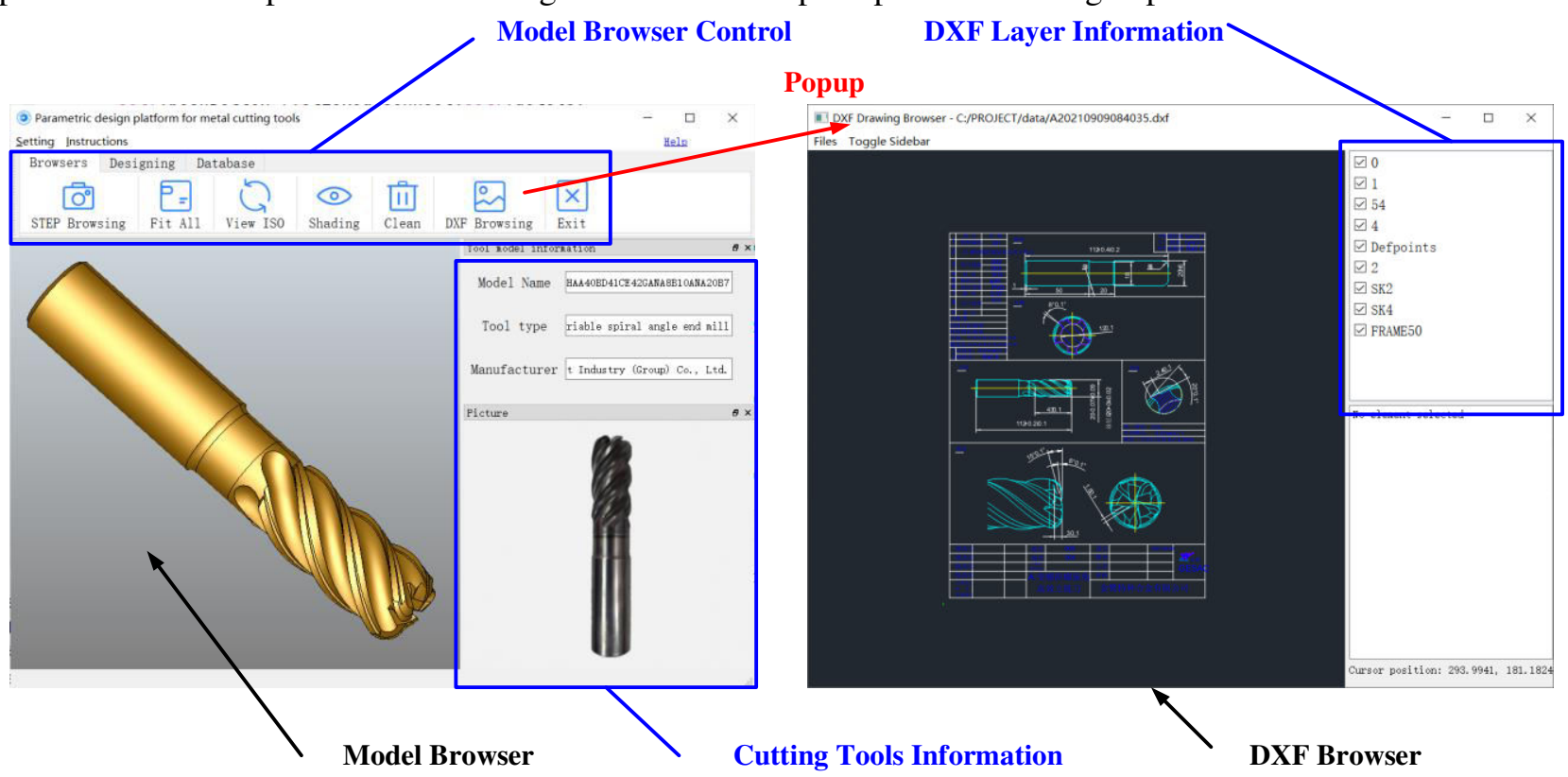

Fig. 12 User interaction module

(2) Parametric design module

The user can quickly generate the new tool model shown in Fig. 12 by using PyQt5 to make the parametric 
design interface of the tool model as shown in Fig. 13 and inputting the key design parameters that affect the cutting process. The user can also fill in the title bar information of two-dimensional drawings in the title bar information pop-up window as shown in Fig. 13, The program can directly write the title bar information into the newly generated 2D drawing shown in Fig. 12.

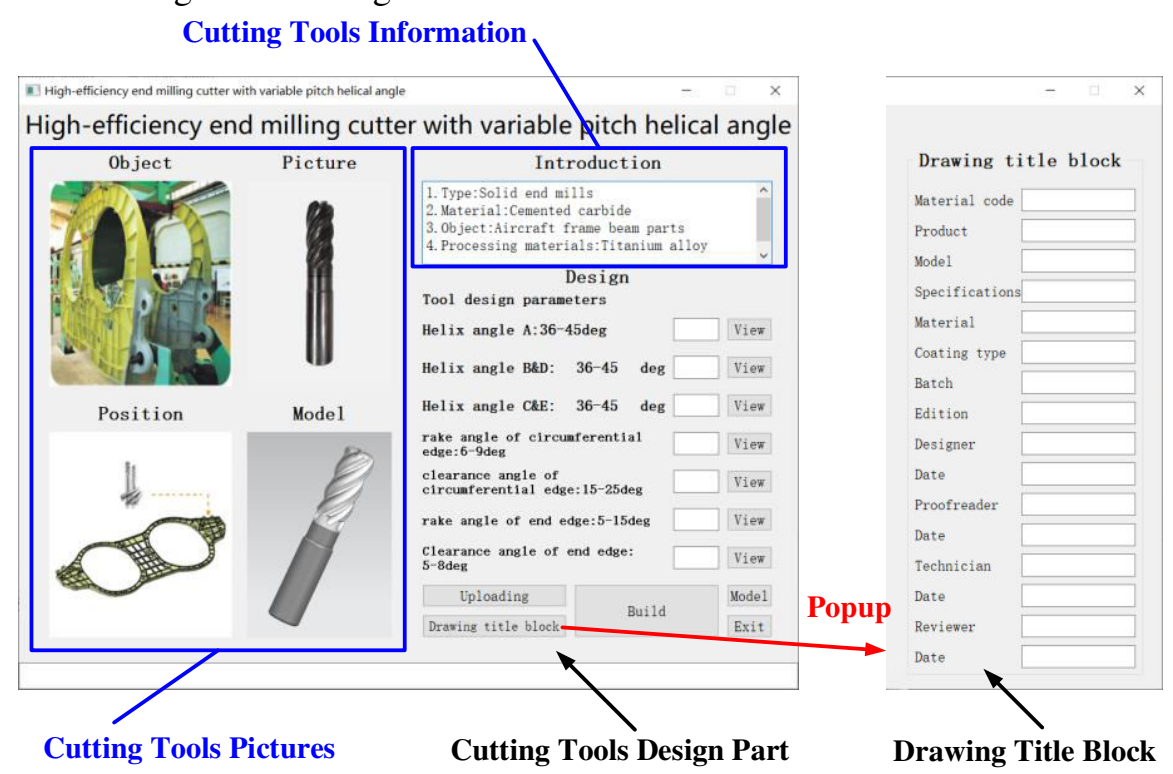

Fig. 13 Parametric design module of cutter

(3) Model database management module

In order to facilitate users' interaction and application of tool model data, this paper uses Linux system to build a cloud database based on MySQL database. According to data categories, the database has established five sub-tables: STEP 3D model, SAT simulation model, DXF 2D drawing, account information and operation records. Users can manage the database through the model database management interface as shown in Fig. 14, and at the same time, the logic program can upload the user's operation record and IP address to the operation record sub-table, which provides guarantee for the database security.

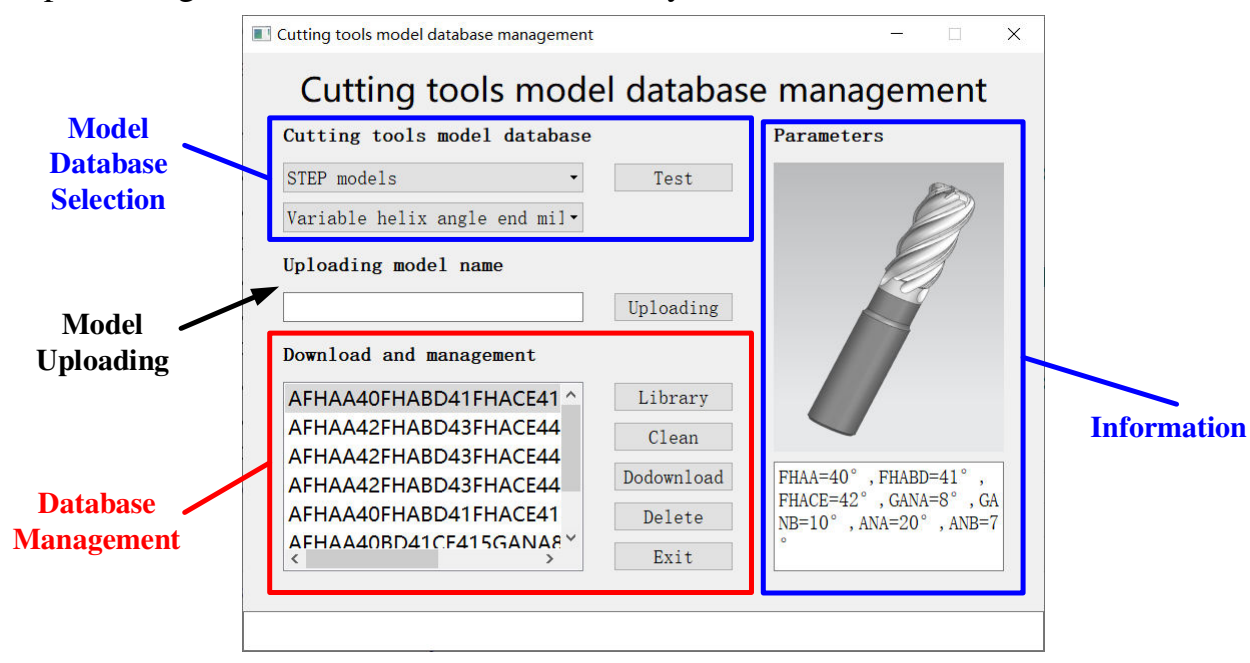

Fig. 14 Model database management module

\subsection{Programming}

(1) Main program

The function of the main program is to connect the interface program with the logic program. In this paper, the interface program and logic program are separated for programming. This method has the advantages of clear code structure and high programming efficiency, and the modification of a single program will not affect other programs.

(2) Parametric modeling logic program 
Logic program is the core program of the whole tool parametric design platform, which mainly realizes the functions of obtaining interface input parameters, distinguishing parameters, modifying expression files and running parametric drive files. The principle of this function is shown in Fig. 15. The logic also plays the role of transferring parameters and controlling interface actions.

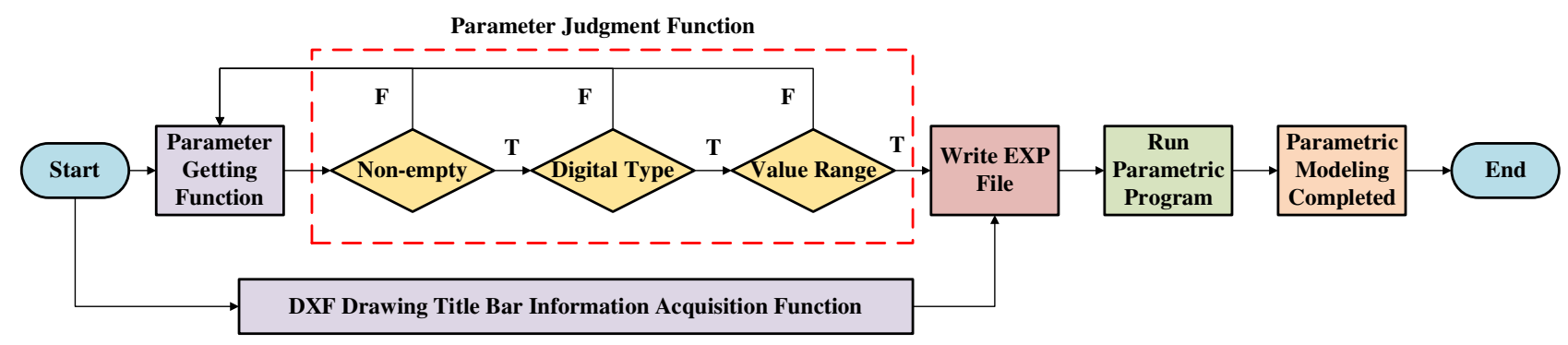

Fig. 15 Main functional principle of logic program

(3) Database logic program.

The model management logic program mainly realizes the functions of uploading, downloading and deleting model data. The logic also plays the role of database content display and interface action control. In addition, the program can compare the data uploaded by users with the original data in the database to ensure that there is no duplicate data in the database.

\subsection{Design examples}

Based on the ISO/TS 13399-303 [28] standard, the parametric model of high-efficiency end mill with variable pitch and helix angle is established as shown in Figure 16a. Similarly, the parameterized model of special tool for valve seat ring as shown in Fig. 16b is established based on ISO/TS 13399-204 [29] and ISO/TS 13399-312 [30] standards. Based on ISO/TS 13399-201 [31] and ISO/TS 13399-308 [32] standards, a parametric model of large feed milling cutter is established as shown in Fig. 16c. According to the statistics of fig. 17, it takes about 50 minutes to build the 3D model of the tool and draw the 2D drawing by the traditional method. While it takes only 5 minutes from inputting design parameters to generating tool models and two-dimensional drawings by using this platform. And the modeling and drawing efficiency is improved by $90 \%$.

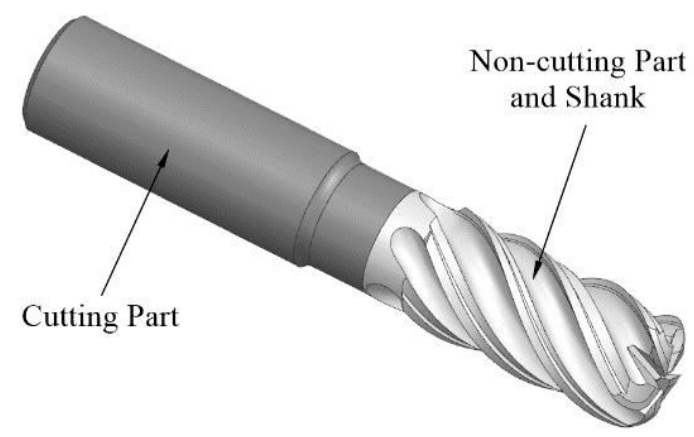

a. High-efficiency end mill with variable pitch and helix angle

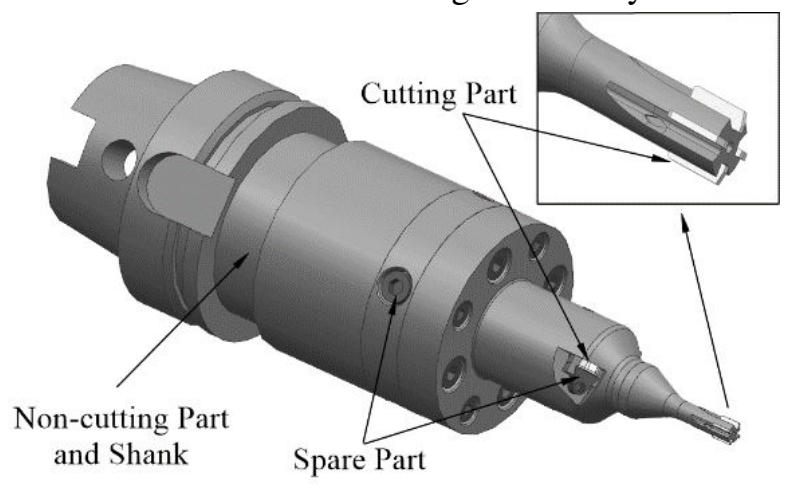

b. Special cutter for valve seat ring

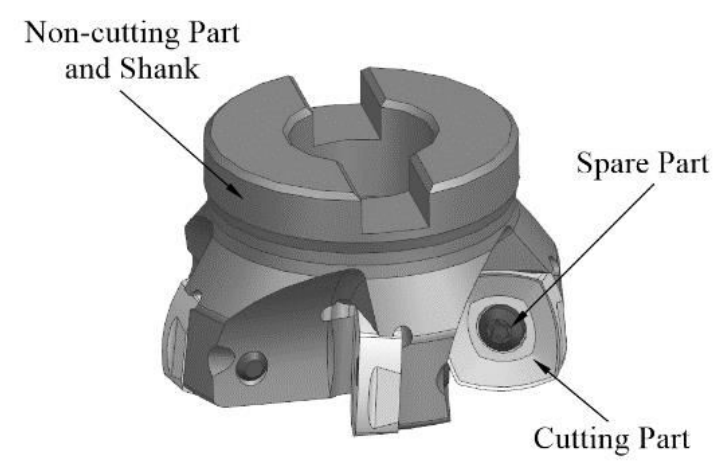

c. High feed milling cutter 
Fig. 16 Platform design example

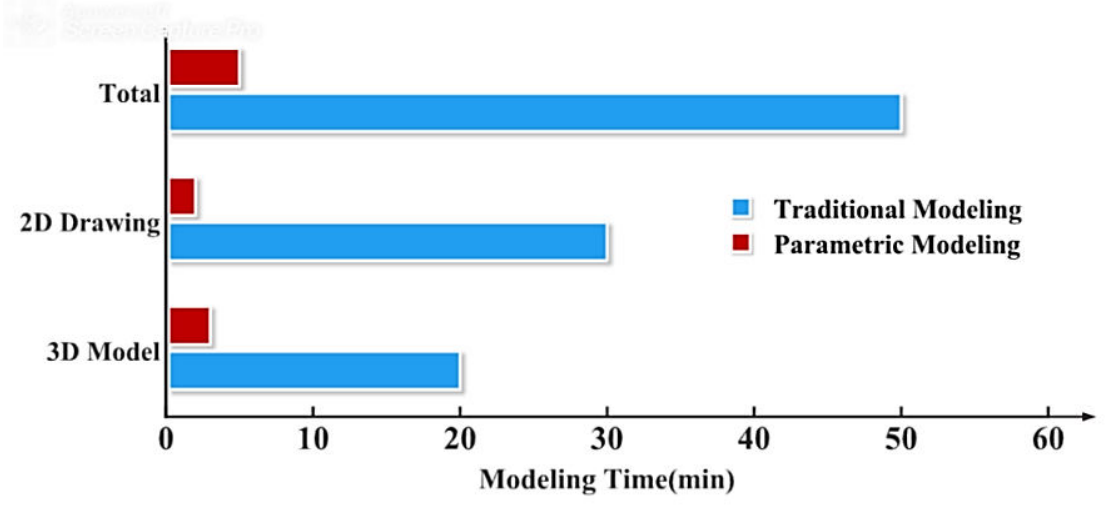

Fig. 17 Modeling efficiency

\section{Conclusions}

This paper introduces the structural characteristics of typical cutting tools used in manufacturing industries, analyzes the difficulties in tool model design, and puts forward the necessity of developing a parametric design platform for cutting tools. In this paper, an integrated design method for complex tools is proposed, which integrates cutting edge topography, CAD software, CAE software, database and optimization algorithm. Parametric tool design platform is a part of it, to provide a standardized tool model. The parameter equation of continuous edge curve of circumferential edge curve and circular edge curve is established by using equal lead helix of rotary cutter. Aiming at the problems of long design cycle and low design efficiency of complex cutting tools with customized requirements, this paper realizes parametric modeling of cutting tools based on the process construction method of generating history. Using Python as the bottom language, the tool parametric design platform is developed by the method of secondary development of commercial CAD software. The conclusions are as follows:

(1) Tool parametric design platform can quickly generate 2D drawings, 3D models and simulation models, and realize the cloud storage function of model data.

(2) The tool model established by the platform following ISO 13399 standard has good tool information interactivity. The platform is separated from the main interface of NX software, which is easy to operate and has low requirements for hardware configuration.

(3) The platform has realized the parametric design of many kinds of tools, which has the characteristics of good integration and good human-computer interaction. Compared with conventional modeling, the efficiency of modeling with this platform has increased by $90 \%$.

\section{References}

1. Leszek A. Dobrzański (2006) Significance of materials science for the future development of societies. Journal of Materials Processing Tech, 175(1-3), 133-148

2. Li AH, Zhao J, Pei ZQ, Zhu NB (2014) Simulation-based solid carbide end mill design and geometry optimization. International Journal of Advanced Manufacturing Technology, 71(9-12), 1889-1900

3. Tzotzis A, García-Hernández C, Huertas-Talón J-L, Kyratsis P (2020) CAD-Based Automated Design of FEA-Ready Cutting Tools. Journal of Manufacturing and Materials Processing, 4(4), 104

4. Tzotzis A, García-Hernández C, Huertas-Talón J-L, Kyratsis P (2020) Influence of the nose radius on the machining forces induced during aisi-4140 hard turning: a cad-based and $3 \mathrm{~d}$ fem approach. Micromachines, 11(9), 798

5. Krol O, Sokolov V (2019) Parametric Modeling of Gear Cutting Tools. Advances in Manufacturing II, 4:311

6. Nasri A, Slaimi J, Bouzid Sai W (2016) 3D Parametric Modelling of Milling Cutter Geometry from 
Analytical Analysis. International Journal of Science, Technology and Society, 4(2): 35-40

7. Chang L (2016) A Parametric Design of Ball End Mill and Simulating Process. Dissertation, Concordia University

8. Zhu J (2016) Parametric Modeling Program of Fillet End Mill. Dissertation, Concordia University

9. Chen H (2015) A New Method of Modeling Flank and Fillet Rake Surfaces of Fillet End-mills. Dissertation, Concordia University

10. Ding MN, Ji W, Wang YW, Zuo DG, Cheng YN (2014) Cutting Tool CAD / CAE Integrating System Modeling. Materials Science Forum, 800-801, 698-702

11. Ding YP, Liu XL, Zhou XY, Shi HN, Li J, Zhang R (2013) The Secondary Development of Milling Forces Simulation System of Ball End Mill Based on UG. Advanced Materials Research, 820, 157-161

12. Ji SY, Liu XL, Ma DL, Ding YP, Wu J (2011) Parametric Design of Face Milling Cutter Based on UG Template Model. Advanced Materials Research, 188, 336-339

13. Ji SY, Liu XL, Yan FG, Yue CX, Zhao XF (2010) Layer Face Milling Cutter Parametric Modeling and Modal Analysis. Advanced Materials Research, 102-104, 605-609

14. Ding H, Yang ZJ, Wang XW, Ding ZY (2010) The Study of CAD/CAE Integrated Technology in Network Environment. Advanced Materials Research, 145, 567-572

15. Chen N, Yan B, Yuan Y, Li L, He N (2020) Research on Parametric Design System of Micro-mills. Journal of Mechanical Engineering (23),185-192

16. Wu XF, Luo W, Yang SC (2016) Rapid Modeling of BTA Deep-Hole Drill Based on Customized Development of NX. Materials Science Forum, 836-837, 476-483

17. Iulian S, Flori B, Traian B (2015) Parametric Design of Gear Hob Cutter. Applied Mechanics and Materials, 809-810, 736-741

18. Yue CX, Yan FG, Li LB, You HY, Yu QJ (2014) Parametric Design of Ball-End Milling Tools for High Speed Milling. Materials Science Forum, 800-801, 484-488

19. Ma DL, Wang Y, Ji SY, Ding YP, Li WT (2011) UG-Based Parametric Design of Copy Milling Cutters. Advanced Materials Research, 188, 697-700

20. Basova TV, Basova MV (2019) Problems of using tool assemblies in cam system. IOP Conference Series: Earth and Environmental Science, 378(1), 012055 (5pp)

21. Zarkti H, Rechia A, Mesbahi AE (2017) Automatic Tool Selection System based on STEP_NC and ISO 13399 Standards. Transactions on Machine Learning and Artificial Intelligence, 5(4):217-230

22. Lundgren M, Hedlind M, Kjellberg T (2016) Model driven manufacturing process design and managing quality. Procedia CIRP, 50, 299-304

23. Helgoson M, Kalhori V (2012) A conceptual model for knowledge integration in process planning. Procedia CIRP, 3(1), 573-578

24. Kaymakci M, Kilic ZM, Altintas Y (2012) Unified cutting force model for turning, boring, drilling and milling operations. International Journal of Machine Tools \& Manufacture, 55(none), 34-45

25. Botkina D, Hedlind M, Olsson B, Henser J, Lundholm T (2018) Digital twin of a cutting tool. Procedia CIRP, $72,215-218$

26. ISO 13399 - 1: 2006, Cutting tool data representation and exchange-Part 1: Overview, fundamental principles and general information model.

27. K.J.A. Brookes (2019) ISO 13399 what is it and why do we need it? Metal Powder Report, 74(6), 305-307

28. ISO/TS 13399 - 303: 2016, Cutting tool data representation and exchange - Part 303: Creation and exchange of 3D models - Solid end mills

29. ISO/TS 13399 - 204: 2016, Cutting tool data representation and exchange - Part 204: Creation and exchange of 3D models - Inserts for reaming

30. ISO/TS 13399 - 312: 2016, Cutting tool data representation and exchange - Part 312: Creation and exchange 
of 3D models - Reamers for indexable inserts

31. ISO/TS 13399 - 201: 2014, Cutting tool data representation and exchange - Part 201: Creation and exchange of 3D models - Regular inserts

32. ISO/TS 13399 - 308: 2016, Cutting tool data representation and exchange - Part 308: Creation and exchange of 3D models - Milling cutters with arbor hole for indexable inserts 